\title{
Relationship of photosynthetic rate and edaphic factors to root carbohydrate trends in honey mesquite
}

\author{
CHANGGUI WAN AND RONALD E. SOSEBEE
}

\begin{abstract}
Total nonstructural carbohydrate (TNC) concentration in honey mesquite (Prosopis glandulosa var. glandulosa) roots and its relation to current photosynthetic rate and selected soil parameters were examined on 2 upland soils. Root carbohydrate recharge rates were generally greater in trees on a sandy loam site than those on a clay loam site during the spring rainy season because of higher photosynthetic rates and more apparent root growth. Recharge rate was greater on the clay loam site during midsummer, which was related to higher soil water potential. Root carbohydrate recharge was less sensitive to a moderate water stress (dawn xylem water potential ranged from -1 to $-1.6 \mathrm{MPa}$ ) than was photosynthesis; but it was more sensitive to severe water stress (dawn xylem water potential ranged from -1.9 to $2.4 \mathrm{MPa}$ ) than was photosynthesis. Effective control of honey mesquite with foliar-applied herbicides is determined by photosynthetic rates and TNC trends as they are influenced by both soil temperature and soil water content. Higher photosynthetic rates and greater amounts of root TNC are related to higher soil temperature and higher soil water content.
\end{abstract}

\section{Key Words: mesquite, TNC/photosynthesis}

Honey mesquite (Prosopis glandulosa var. glandulosa) is considered a widespread "pest" plant occurring throughout much of the Southwest and presently occupies more than half of Texas' rangeland (Soil Conservation Service 1982, unpublished data). Much effort has been expended to chemically control this shrub. Stage of growth and the physiological conditions of the plant are important

Authors are graduate research assistant and professor, Department of Range and Wildlife Management, Texas Tech University, Lubbock 79409. Wan's current address is Grassland Research Institute, Lanzhou, Ganzu Province, Peoples Republic of China.

Contribution No. T-9-515, College of Agricultural Sciences, Texas Tech University, Lubbock 79409.

Manuscript accepted 8 June 1989. parameters in determining the optimum time to spray honey mesquite (Sosebee 1984).

Fisher et al. (1946) suggested that water content in the upper 30 $\mathrm{cm}$ of soil was the most significant variable in controlling mesquite. Later it was found that maximum herbicidal control of mesquite was obtained from mid-May through June when photosynthates were translocating to the underground parts of the plant (Fisher et al. 1970). During this period, leaves are fully mature and the soil is usually moist, which is conducive for active growth. Fisher (1950) obtained maximum mesquite kill by applying 2,4,5-T (2,4,5trichlorophenoxy acetic acid) 50 to 90 days after the first leaves appeared. Dahl and Sosebee (1984) found that the highest rootkil with herbicides was obtained when carbohydrates were translocating to the root and basal buds. This occurred 42 to 63 days and 72 to 84 days after budbreak. They also indicated that from 42 to 84 days after budbreak, soil temperature within the active rooting zone $\left(30\right.$ to $60 \mathrm{~cm}$ ) should exceed $24^{\circ} \mathrm{C}$. If soil temperature was below $24^{\circ} \mathrm{C}$, control was minimal (Dahl et al. 1971). Meyer et al. (1983) found daily maximum photosynthetic rates were positively correlated with canopy reduction and mortality of sprayed honey mesquite. Export of sucrose from leaves depends on current photosynthesis of plants, therefore, it is assumed that root carbohydrate trend is related to photosynthetic capacity.

Mesquite is effectively controlled with foliar-applied herbicides when the soil temperature is above $24^{\circ} \mathrm{C}$ and the TNC trend is toward the roots. However, control is ineffective when the trend is toward the roots, but soil temperature is less than $24^{\circ} \mathrm{C}$. Therefore, this research was conducted to evaluate the effect of soil temperature and water content on root TNC trends and photosynthesis within mesquite. It was also designed to test the relationship between root TNC patterns and (1) soil temperature and water content, and (2) photosynthesis. 

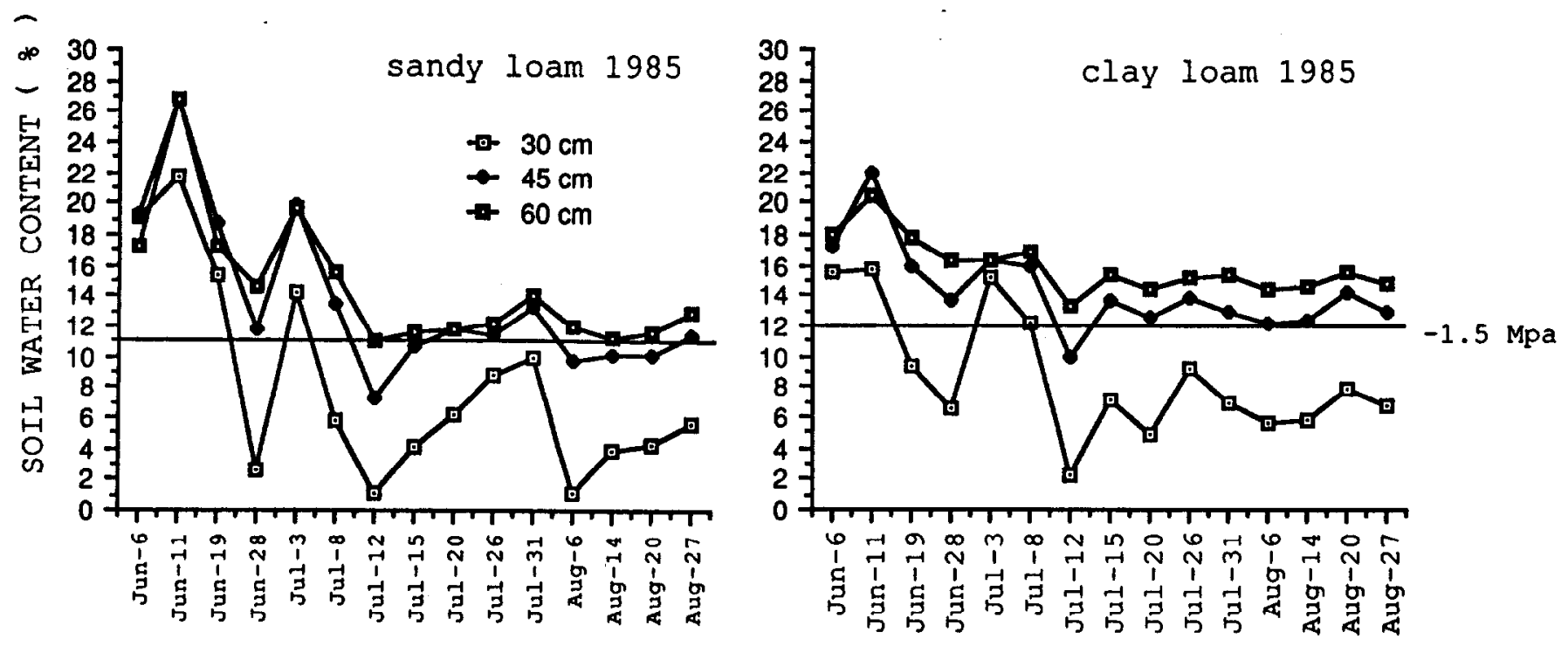

Fig. 1. Soil water content (\%) at 30 to $60-\mathrm{cm} 6$ June through 27 August 1985 on a sandy loam and a clay loam range site on the Texas Tech University campus. The horizontal lines on the vertical axis represent the water content at $\mathbf{- 1 . 5}$ MPa matric potential.

\section{Experimental Procedure}

The study area was on the Texas Tech University campus, Lubbock. Two upland range sites with different soils were chosen as study areas: (1) an Amarillo fine sandy loam (fine-loamy, mixed, thermic Aridic Paleustalfs) and (2) an Olton clay loam (fine, mixed, thermic Aridic Paleustolls). Climate of the area is semiarid with an average annual precipitation of $450 \mathrm{~mm}$. Monthly and annual precipitation vary considerably, with May and June being the wettest months. The average frost-free period is 211 days, from early April to early November. Vegetation in the area is characterized by a shrub stratum of honey mesquite and a herbaceous stratum dominated by buffalograss (Buchloe dactyloides), blue grama (Bouteloua gracilis), and broom snakeweed (Xanthocephalum sarothrae). The experiment was conducted on the 2 sites in 1985 and 1986.

An open system was used to measure photosynthesis. A pump

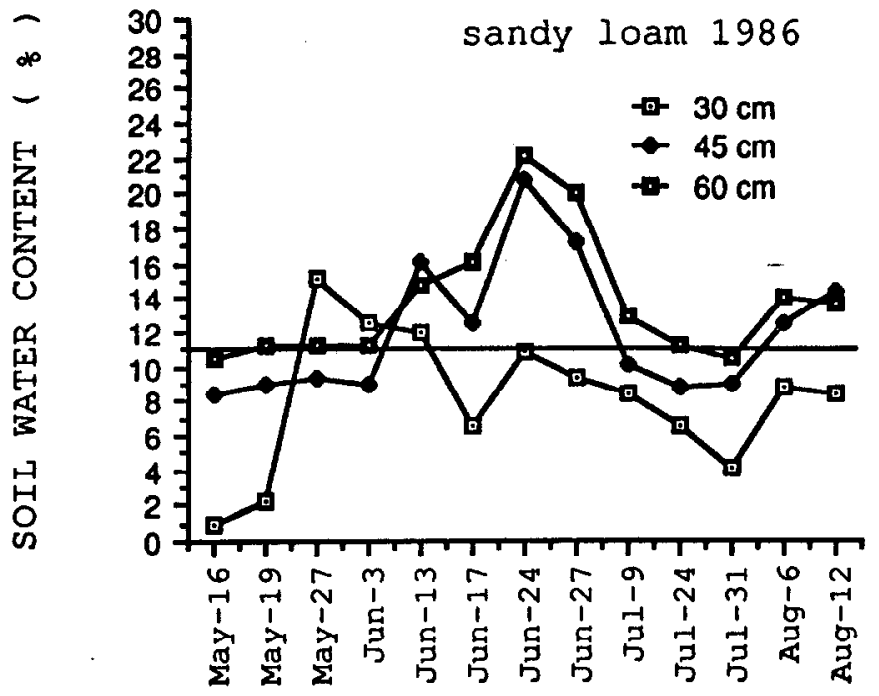

drew air from the atmosphere and supplied it to a leaf chamber ( 10 $\times 15 \times 19 \mathrm{~cm})$. The leaf chamber was constructed of plexiglas which allowed approximately $95 \%$ transmission of the available illumination and was equipped with a fan to promote air movement and a water circulator to aid in temperature control. The water circulator consisted of looped copper tubing at the bottom of the chamber. The air stream inlet and outlet were on opposite sides of the chamber to assure mixing of the air within the chamber. The chamber was heated by incident solar radiation and cooled by cold water flowing through the circulator. A thermostat regulated the circulator and maintained the chamber temperature within $2^{\circ} \mathrm{C}$ of ambient temperature. The air intake was placed upwind from the leaf chamber to assure an uncontaminated air supply. A differential of less than $40 \mathrm{ppm} \mathrm{CO}_{2}$ was maintained by adjusting the rate of air flow to the chamber.

The $\mathrm{CO}_{2}$ concentration at the inlet port and $\mathrm{CO}_{2}$ depletion by photosynthesis were measured by analyzing syringe samples using

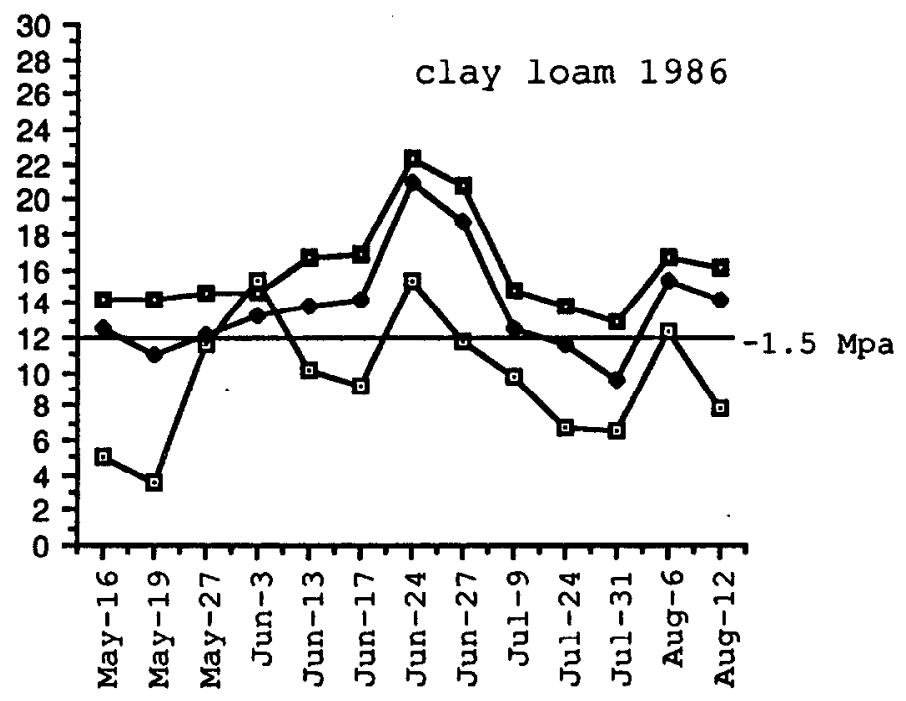

Fig. 2. Soil water content (\%) at 30 to $60-\mathrm{cm} 16$ May through 12 August, 1986 on a sandy loam and a clay loam range site on the Texas Tech University campus. The horizontal lines on the vertical axis represent water content at $-1.5 \mathrm{MPa}$ matric potential. 
a Beckman 865 infrared gas analyzer (IRGA) as described by Clegg et al. (1978). Syringe samples were dried prior to analysis. Inlet and outlet $\mathrm{CO}_{2}$ concentration measurements were each replicated 3 to 4 times for photosynthetic rate determination.

$\mathrm{CO}_{2}$ exchange rate was measured weekly (weather permitting) on 10 trees on each site for most of the growing season. Paired measurements between the sites were made 7 to 10 times daily (from 0800 to 1700 hours) on 1 branch in the upper canopy of each tree. The time interval from 1 site to the other was about 15 minutes. The sample branch was harvested and leaves were removed from the branch for leaf area measurements using an electronic leaf area meter. Photosynthetic rate (PS) was calculated according to the following equation (Hanson 1982):

$$
\mathrm{PS}=\mathrm{K} \times \mathrm{F} \times \mathrm{dCO}_{2} / \mathrm{A} \text {, }
$$

Where:

$$
\begin{aligned}
& \mathrm{F}=\text { flow rate of air through the leaf chamber measured in } \\
& \text { liters } / \text { minute, } \\
& \mathrm{dCO}=\mathrm{CO}_{2} \text { concentration depletion after the air passed } \\
& \text { through the leaf chamber, } \\
& \mathrm{A}=\text { leaf area for one side in } \mathrm{dm}^{2} \text {, and } \\
& \mathrm{K}=\text { conversion factor equal to } 1.79 \times 10^{-10} \mathrm{mg} / \mathrm{ppm} / \text { liter } \\
& \text { at } 25^{\circ} \mathrm{C} \text { and } 0.1 \mathrm{MPa} \text {. }
\end{aligned}
$$

Soil water content $(\%)$ was measured with the neutron attenuation technique at $15-\mathrm{cm}$ increments in the profile of 30 to $165 \mathrm{~cm}$. Soil water measurements were taken at 3 locations around the sample trees for each sample period. A pressure membrane plate apparatus (Gardner 1965) was used to develop soil water retention curves down to -1.5 MPa matric potential. Soil matric potentials were estimated from soil water content data using the soil water retention curve. Soil water extraction during any 2 periods was measured by the difference between initial soil water content in the profile and water content in the profile at the end of the period. Soil bulk density determined by the paraffin method was used to convert water content $(\%)$ to water volume $(\mathrm{cm})$ as a measure of the amount of water extraction.

Xylem water potential was measured with a pressure chamber (Scholander et al. 1965). Measurement of photosynthesis and xylem water potential were conducted over 2 years when root carbohydrate data were collected. Soil temperature was measured with thermocouples imbedded in the soil at $15-\mathrm{cm}$ increments in the 15 to $120-\mathrm{cm}$ profile. Soil temperature measurements were made 3 times a day (at 0900,1200 , and 1600 hours) and were replicated 3 times at each depth.

Root samples for carbohydrate analysis were collected biweekly from 5 trees growing adjacent to the trees being used for photosynthesis measurements. Taproots were excavated and samples were chipped from the large portion immediately below the basal bud zone with a hand axe and were frozen with dry ice until they were transported to the lab. In the laboratory, the samples were ovendried for 1 hour at $100^{\circ} \mathrm{C}$ to stop enzymatic activity which catabolizes carbohydrates, and then at $65^{\circ} \mathrm{C}$ for at least 48 hours. After drying, the cortex of the root tissue was separated from the epidermis and the xylary tissue. The epidermis and xylary tissue were discarded and the cortex was saved for TNC analyses. Samples were then ground to pass through a 40-mesh screen and stored for TNC analysis. TNC was extracted from a 0.5-g sample of plant material with acid $(0.2 \mathrm{H} \mathrm{HCl})$ hyd rolysis as described by Smith et al. (1964). Carbohydrate concentration was determined by using spectrophotometry and anthrone reagent (Murphy 1958) with a dextrose standard. Relative abundance of flower and fruit produced by the trees on both sites was monitored throughout the growing season.

A randomized complete block design was used in measuring
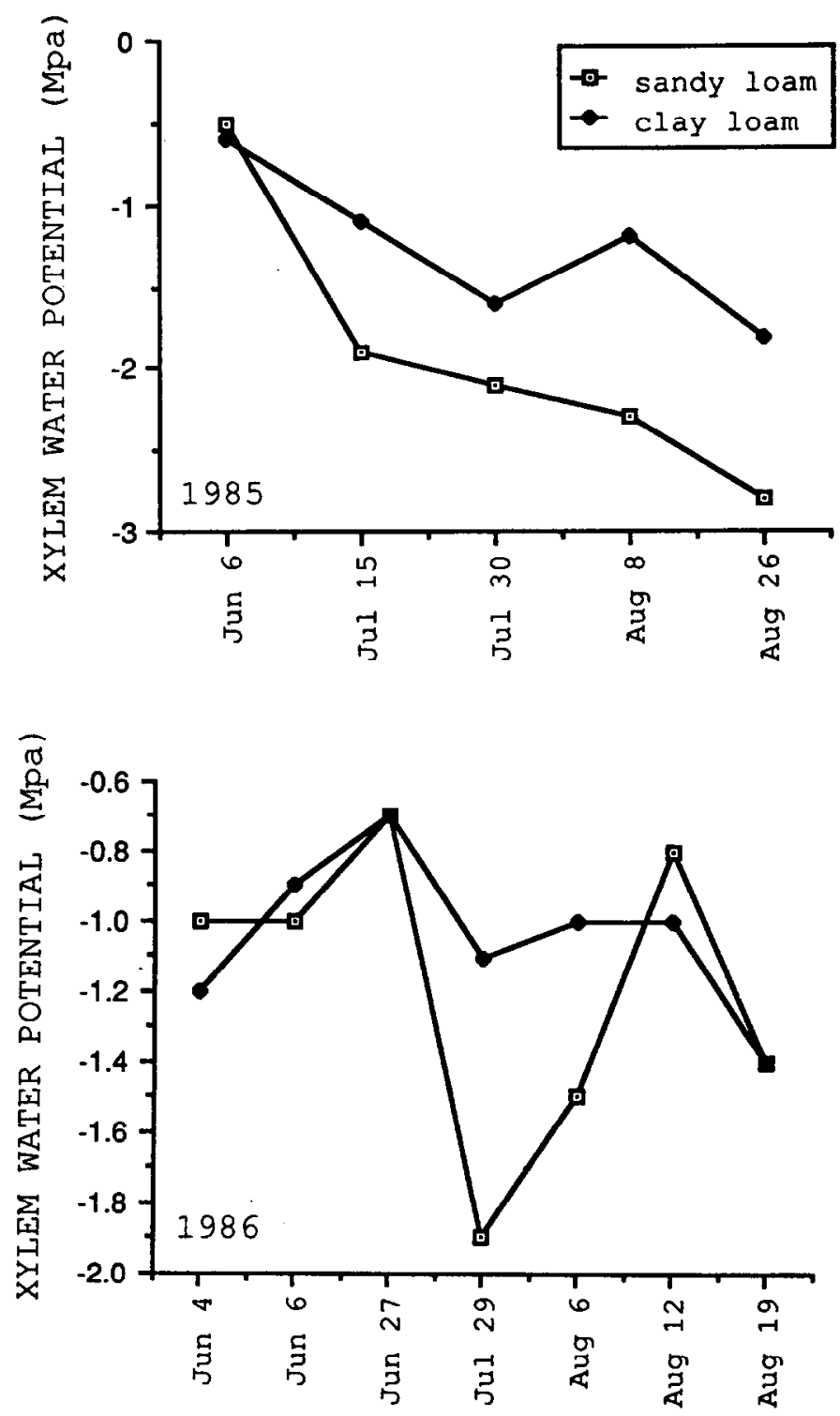

Fig. 3. Dawn xylem water potential (MPa) June through August 1985 and 1986 for trees grown on a sandy loam and a clay loam site on the Texas Tech University campus.

photosynthesis and root TNC. Five trees were randomly selected on 2 sites (treatments) for measurement of photosynthesis. Trees were paired between sites. Photosynthetic rates were measured on each pair of trees on consecutive days (constituting a sampling date). Measurements were repeated throughout the growing season (sample dates). Root TNC data were analyzed using the paired $t$-test. Root TNC values and soil temperatures were subjected to correlation analyses.

\section{Results and Discussion}

\section{Soil Water and Soil Temperature}

Soil water content followed the same pattern for both sites (Fig. 1 and 2). In early June 1985 (Fig. 1) when soil water was at or above field capacity, water depletion was the greatest. The soil water depletion curve was steeper for the higher soil water contents. From 11 June to 28 June 1985, water depletion on the sandy loam site was $15.8 \mathrm{~cm}$, which was $450 \%$ of that on the clay loam site within the 30 to $165-\mathrm{cm}$ profile, the major rooting zone of mesquite (Heitschmidt et al. 1988). 

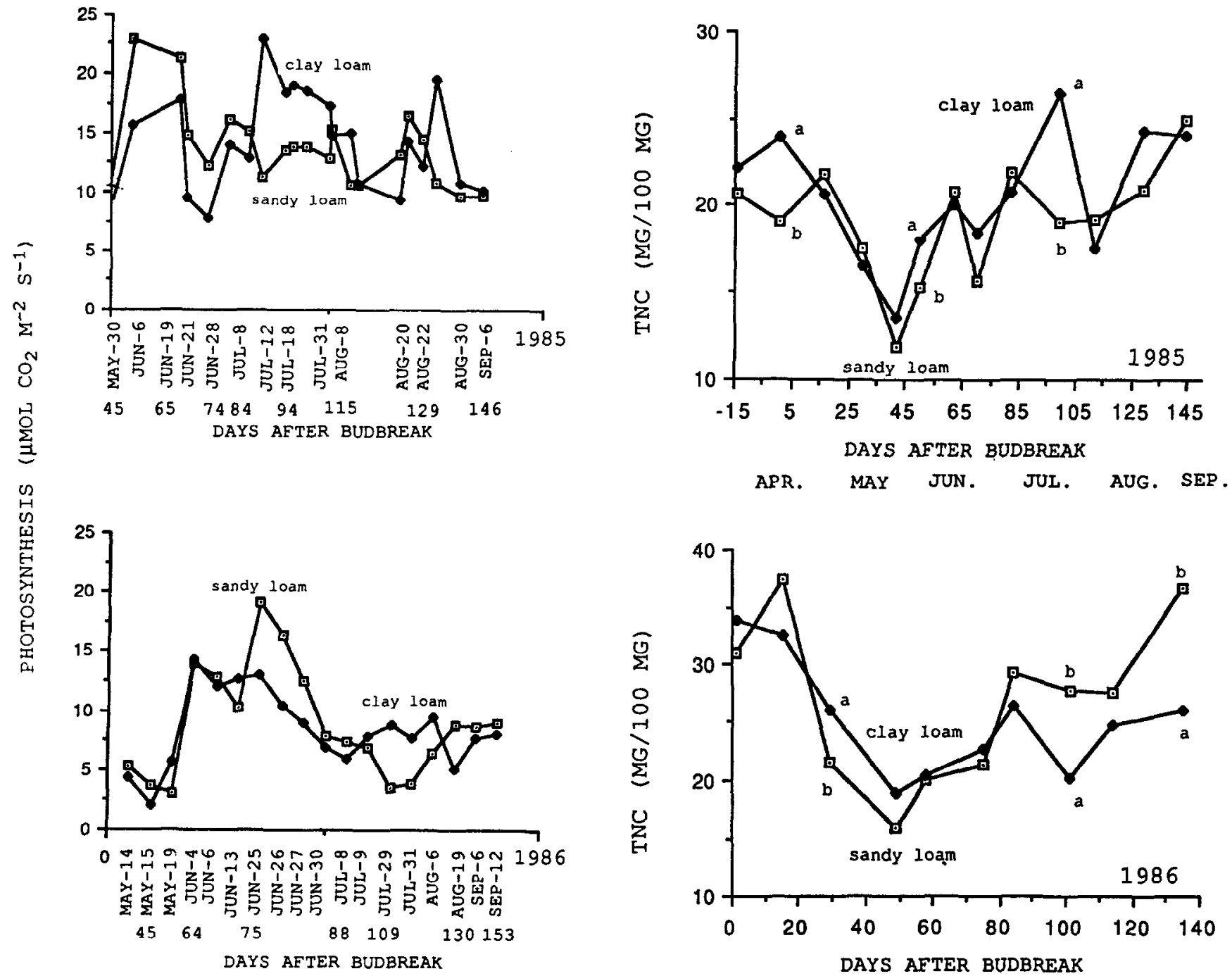

Fig. 4. Seasonal pattern of $\mathrm{CO}_{2}$ uptake $\left(\mathrm{mmol} \mathrm{CO}_{2} \mathrm{~m}^{-2} \mathrm{~s}^{-1}\right)$ of honey mesquite in 1985 and 1986 on a sandy loam and a clay loam range site on the Texas Tech University campus. Each value is an average of 7 to 10 paired measurements during a day.

With onset of summer drought, beginning in early July, water use within the 30 to $165-\mathrm{cm}$ profile of the clay loam site became greater. From 8 July to 26 July, the clay loam soil lost $26 \%$ more water $(6.1 \mathrm{~cm})$ than the sandy loam soil. After $12 \mathrm{July}$, water use on both sites was reduced sharply, especially from the sandy loam. Water content of the clay loam site remained quite high during mid-July (averaging $11 \%$ in 30 to $165-\mathrm{cm}$ profile, $79 \%$ of field capacity) because of the greater water holding capacity and limited consumptive use in the spring. Therefore, more water was extracted from the clay loam during this period. In contrast, there was less extractable water left in 30 to $165-\mathrm{cm}$ profile (averaging $7.3 \%, 57 \%$ of field capacity) of the sandy loam site during the summer. Since mesquite had the largest living biomass on the site, a great proportion of water was used by the trees (Wan 1987).

In mid-July 1985, average soil matric potential at $60 \mathrm{~cm}$ on the sandy loam site was reduced to about $-1.5 \mathrm{MPa}(10.9 \%)$, while on the clay loam site it remained at $-0.7 \mathrm{MPa}(13.4 \%)$. Since the highest water content existed at the $60-\mathrm{cm}$ depth for both sites, these levels represent the highest water potentials in midsummer. Plants on the sandy loam site were under more severe water stress than those on the clay loam site. Dawn xylem water potentials

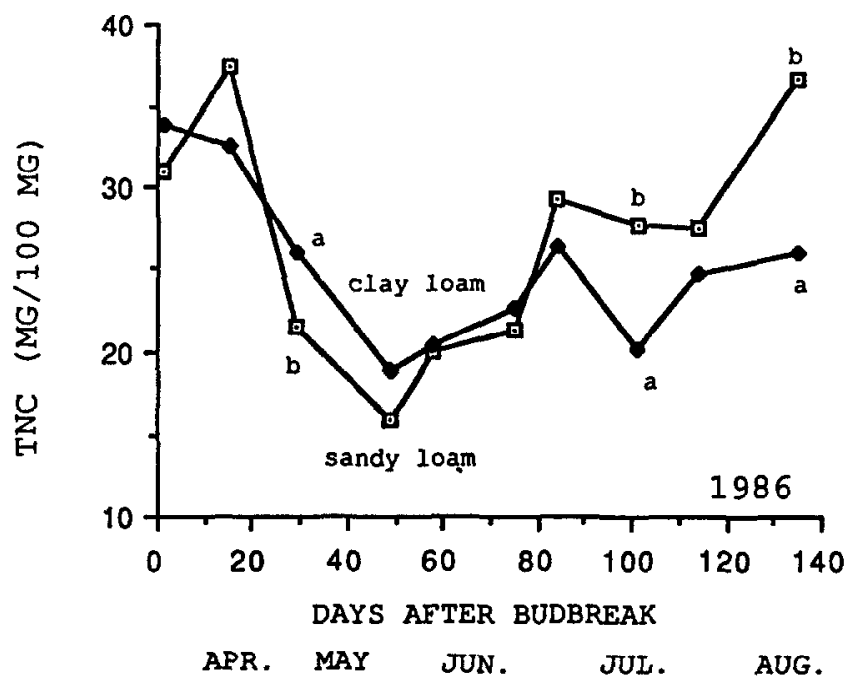

Fig. 5. Seasonal trend in root total nonstructural carbohydrate level $(\mathrm{mg}$ $100 \mathrm{mg}^{-1}$ ) in 1985 and 1986 . The means within a date followed by letters are significantly different $(P<0.05)$. The means within a date not followed by letters are not different.

during early August, 1985 , were -2.1 and $-1.2 \mathrm{MPa}$, on the trees from the sandy loam and the clay loam site, respectively (Fig. 3).

\section{Seasonal Patterns of Photosynthetic Rates on the 2 Sites}

Photosynthetic rates were greater $(P<0.01)$ in trees growing on the sandy loam site than in those growing on the clay loam site in the rainy season of both years ( $6 \mathrm{June}$ to $8 \mathrm{July}$ in $1985 ; 25 \mathrm{June}$ to 9 July in 1986) (Fig. 4). Higher photosynthetic rates were probably associated with greater water uptake on the sandy loam site. Because of the greater withdrawal of water on the sandy loam soil in the early part of the year, the plants became water stressed sooner and the stress became more severe later in the season. Thus, in the summer, the trees on the sandy loam site had lower photosynthetic rates than those on the clay loam site $(P<0.01)$ (Fig. 4), except in early August when the drought was relieved by rainfall.

\section{Root TNC Pattern}

Root TNC concentration of mesquite roots in 1985 (Fig. 5) was similar to the general pattern as previously reported by Wilson et al. (1975), Seipp (1982), and Dahl and Sosebee (1984). Root TNC 
dropped to a minimum level $\mathbf{4 5}$ days after budbreak. Three root recharge events occurred from late May through August. The first 2 recharge events occurred in late May and late June, when the leaves were fully mature and actively photosynthesizing. This is the most susceptible period for chemical control of mesquite. During this period, trees on the sandy loam site had greater root recharge rates than those on the clay loam site (Fig. 5). In early June, plants on the sandy loam site had a lower root TNC concentration $(P<0.05)$ than those on the clay loam site. The rates of photosynthesis in trees on the sandy loam site were greater than those on the clay loam site during June, which made the shoots from trees on the sandy loam site a stronger "source". This could explain the more rapid root TNC replenishment in trees on the sandy loam site. Simlar data were reported by Seipp (1982).

The third root TNC recharge occurred in mid-July when the plants had completed pod formation and more photosynthates were available to be translocated to the roots. Because of water stress, plants on the sandy loam site in this period were not able to maintain their photosynthetic rates at comparable levels. Phloem loading might be affected by lack of assimilate. Root TNC concentration declined and was not replenished until mid-August. Trees on the more mesic clay loam site, however, had greater assimilation rates which were correlated with a rapid root TNC recharge.

Root TNC concentration pattern for 1986 (Fig. 3) was different from that for $1985 ; 1985$ was a wet year with $560 \mathrm{~mm}$ precipitation, which was $115 \mathrm{~mm}$ above average. Also, most rainfall occurred in May, June, and July when plants were actively photosynthesizing. Favorable soil moisture conditions allowed the mesquite trees to photosynthesize at higher rates and greater amounts of assimilates were available for the roots. Therefore, root TNC recharge occurred 3 to 4 times in the growing season. Adequate soil moisture, higher photosynthesis, and more rapid TNC recharge resulted in higher root TNC concentration in the spring of 1986 . In contrast, root TNC concentrations were much lower in the spring of 1985 since 1984 had a dry growing season with a precipitation of $350 \mathrm{~mm}, 90 \mathrm{~mm}$ below average.

Trees on the sandy loam site had a more rapid root recharge May through June than those on the clay loam site, similar to 1985. In the spring, greater root TNC depletion occurred in trees growing on the sandy loam site than on the clay loam site $(P<0.05)$, thus creating a stronger sink in the roots.

In addition, reproductive processes were influenced differently on the 2 sites by spring water stress. Reproductive processes of honey mesquite were most sensitive to soil water deficit than were photosynthetic rates. Many flowers and heavy fruit loading occurred in June of 1985 on both sites when soil moisture was not limiting. The flower number and overall photosynthetic capacity were reduced in the dry spring of 1986 compared to 1985 , but there was no difference in photosynthetic rates during 14 May to 17 June between trees on the 2 sites $(P<0.05)$. The clay loam soil had a higher water potential $(-0.4 \mathrm{MPa})$ than the sandy loam soil $(-0.7$ $\mathrm{MPa}$ ) at the $60-\mathrm{cm}$ depth. However, reproductive processes of trees on the more xeric sandy loam site were influenced to a greater extent by water stress. On the more mesic clay loam, flowers and pods appeared in less abundance than in 1985. Trees on the sandy loam site had fewer flowers and almost all aborted. When flowers were aborted on the sandy loam site, more assimilates were available for root growth and more rapid root TNC recharge was possible.

Root TNC recharge was inhibited by severe soil water deficit in the dry summers. The highest soil matric potential was below -1.5 $\mathrm{MPa}$ and dawn xylem water potential was approximately $-2 \mathrm{MPa}$ on the sandy loam site. In late June, photosynthetic rates of the trees were reduced to 3 to $6 \mu \mathrm{mol} \mathrm{CO} \mathrm{m}^{-2} \mathrm{~s}^{-1}$ on the sandy loam site, which was less than half that in June. Crider (1955) showed that $50 \%$ of defoliation of several grass species would cause cessation of root elongation. If this is true for honey mesquite, we speculate that a $50 \%$ reduction in photosynthetic rates would have similar effects-it would slow or, perhaps, stop root growth. In midsummer, root TNC concentration on the sandy loam site remained unchanged. This might suggest that photosynthate consumption by limited root growth and maintenance is balanced by limited supply from the shoots. In the hot, dry summer, mesquite trees have their maximum leaf area (Nilsen et al. 1984). To maintain such a leaf area at high temperatures, a considerable amount of photosynthate must be consumed. With low photosynthesis and high maintenance cost in midsummer, the downward carbon flow would be severely affected.

There was a considerable increase in root TNC concentration in trees on the more mesic clay loam site during midsummer in both years. Root metabolic activity in trees on this site was high as indicated by the more rapid root TNC depletion. Photosynthesis on the clay loam was not severely reduced by the moderate water stress (matric potential at $60-\mathrm{cm}$ depth was $-0.7 \mathrm{MPa}$ and dawn xylem water potential was approximately $-1 \mathrm{MPa}$ ) in summer 1986. An average of $8 \mu \mathrm{mol} \mathrm{CO}_{2} \mathrm{~m}^{-2} \mathrm{~s}^{-1}$ was maintained, which was twice that of trees on the sandy loam. This provides more assimilates available for the roots.

Under moderate soil water deficit (dawn xylem water potential -1 to $-1.6 \mathrm{MPa}$ ), as occurred on the clay loam site in midsummer of both years, leaf expansion and photosynthesis were inhibited, but the root TNC concentration was still increasing. This suggests that development of roots had gained a higher priority in the carbon budget of the plant. It is an advantage for the plant to allocate more carbon for root growth so water uptake capacity can increase. This is evidenced by a greater water extraction from the clay loam in midsummer. Mild water stress in mesquite causes photosynthesis to decrease, but has little effect on root TNC recharge. However, with increasing stress, downward carbon flow is more affected than photosynthesis.

\section{Management Implications}

Mesquite trees growing on bottomland or clay soils have been more difficult to kill with herbicides than those growing on coarser-textured soils. Low soil temperature has been shown to be a major reason for this difficulty (Dahl et al. 1971).

Honey mesquite growing in the Rolling Plains, Edwards Plateau and Trans-Pecos of Texas often does not respond favorably to herbicide application during the optimum spray period (usually late May). Likewise, mesquite trees growing on bottomland sites or clay soils are more difficult to control than those growing on upland sites and coarser-textured soils. One reason for this unfavorable response to herbicides is low soil temperature in the upper rooting zone (Dahl et al. 1971, Sosebee 1984). Even though the soil temperature is often below the minimum threshold of $24^{\circ} \mathrm{C}$ in late spring (Dahl et al. 1971), the TNC concentration increases in the roots, indicating a strong sink relationship. Yet, control from foliar-applied herbicides is difficult to obtain under these conditions. Our results indicate that TNC trends and photosynthetic rates follow very similar patterns. In mid- to late May (40 to 45 days post budbreak) both TNC concentrations and photosynthetic rates are low. When photosynthetic rates increase and the leaves begin to export significant quantities of carbohydrates, there are many sinks competing for photosynthates; i.e., buds, cambium, flowers, pods, and young leaves. These sinks have a higher priority for receiving photosynthates than the roots (Larcher 1980). Honey mesquite growing in the northern Rollings Plains of Texas often does not respond to herbicide application in late May when root carbohydrates are increasing because the soil temperature at $45 \mathrm{~cm}$ is less than $24^{\circ} \mathrm{C}$ (Sosebee 1984). Higher soil temperature depletes root TNC by stimulating root growth and steepens the carbohy- 
drate concentration gradient from shoot to root. Poor response to aerially applied herbicides at low soil temperatures apparently is related to downward photosynthate translocation that is not sufficient to transport adequate herbicide to the roots. From early June to early July, 1985, when root carbohydrates were increasing, root carbohydrate concentration had a significant linear correlation with the soil temperature $\left(P<0.05 ; r^{2}=0.83\right)$.

Trees on the sandy loam site generally had greater photosynthetic rates than trees on the clay loam site during a wet spring. Therefore, a greater amount of downward carbohydrate translocation could be expected. The soil water deficit on sandy loam sites during a dry spring usually represents a moderate water stress. Downward carbohydrate translocation increases somewhat, because of much reduced expansion growth and reproductive potential. Therefore, more photosynthates tend to be transported to the roots of the trees growing on sandy loam soil than in those growing on heavier soils.

It is generally recommended (Sosebee 1984) that herbicides should not be applied when plants are water stressed. However, for facultative phreatophytes like mesquite, a moderate water stress favors sugar translocation to the roots. Therefore, a mild water stress does not indicate unfavorable environmental conditions for spraying. This contention is supported by a recent experiment (Mayeux 1987) in which higher mortality and canopy reduction of mesquite was obtained when herbicide was applied in May and September than in July. It would be desirable to spray if water stress inhibits reproductive growth, but only mildly depresses photosynthesis.

\section{Literature Cited}

Clegg, M.D., C.Y. Sullivan, and J.D. Eastin. 1978. A sensitive technique for the rapid measurement of carbon dioxide concentrations. Plant Physiol. 62:924-926.

Crider, F.J. 1955. Root growth stoppage resulting from defoliation of grass. U.S. Dep. Agr. Tech. Bull. 102.

Dahl, B.E., and R.E. Sosebee. 1984. Timing - the key to herbicidal control of mesquite. Management Note 2. Dep. of Range and Wildl., Texas Tech Univ., Lubbock.

Dahl, B.E., R.B. Wadley, M.R. George, and J.T. Talbot. 1971. Influence of site on mesquite mortality from 2,4,5-T. J. Range Manage. 24:210-215.
Fisher, C.E. 1950. The mesquite problem in the Southwest. J. Range Manage. 25:130-136.

Fisher, C.E., J.L. Fults, and H. Hopp. 1946. Factors affecting action of oils and water soluble chemicals in mesquite eradication. Ecol. Monogr. 16:109-126.

Fisher, C.E., E.D. Robison, G.O. Hoffman, C.H. Meadors, and B.T. Cross. 1970.p. 7. In: Aerial application of chemicals for control of brush on rangeland. Texas Agr. Exp. Sta. PR-2801.

Gardner, W.H. 1965. Water content. C.A. Black (ed.) Methods of soil analysis. Part 1. Agronomy 9:31-127.

Hanson, J.D. 1982. Effect of light, temperature and water stress on net photosynthesis in two populations of honey mesquite. J. Range Manage. 35:455-459.

Heitschmidt, R.K., R.J. Ansley, S.L. Dowhower, P.W. Jacoby, and D.L. Price. 1988. Some observations from the excavation of honey mesquite root systems. J. Range Manage. 41:227-231.

Larcher, W. 1980. Physiological plant ecology. (Second ed.) SpringerVerlag, New York, New York.

Mayeux, H.S., Jr. 1987. Application of herbicides on rangelands with a carpeted roller: Timing of treatment in dense stands of honey mesquite. J. Range Manage. 40:348-352.

Meyer, R.E., and J.D. Hanson, and A.J. Dye. 1983. Correlation of mesquite response to herbicides with three plant variables and soil water. $J$. Range Manage. 36:613-615.

Murphy, R.P. 1958. Extraction of plant samples and the determination of total soluble carbohydrates. J. Sci. Food and Agr. 9:714-717.

Nilsen, E.T., M.R. Sharifi, and P.W. Rundel. 1984. Comparative water relations of phreatophytes in the Sonoran Desert of California. Ecology 65:767-778.

Seipp, W.W. 1982. Carbohydrate reserve patterns in honey mesquite during budbreak. M.S. Thesis. Texas Tech University, Lubbock, Texas.

Scholander, P.F., H.T. Hammel, E.D. Bradstreet, and E.A. Hemmingsen. 1965. Sap pressure in vascular plants. Science 148:339-346.

Smith, D., G.M. Paulsen, and C.A. Raguse. 1964. Comparative accuracy and efficiency in determination of carbohydrate from grasses and legume tissue. Plant Physiol. 39:960-962.

Sosebee, R.E. 1984. Physiological, phenological, and environmental considerations in brush and weed control, p. 27-44. In: K. McDaniel (ed.) Brush Management Sym., Proc. Texas Tech Press. Lubbock.

Wan, C. 1987. Photosynthesis and water use in honey mesquite. Ph.D. Diss. Texas Tech Univ., Lubbock.

Wilson, R.T. B.E. Dahl, and D.R. Krieg. 1975. Carbohydrate concentrations in honey mesquite in relation to phenological development and reproductive condition. J. Range Manage. 28:286-89. 